\title{
Más allá de los orígenes: \\ la nueva literatura quebequense
}

Laura LóPEz MORALES

Universidad Nacional Autónoma de México

[...] cualquier cultura nacional en fin de cuentas, es un proceso dinámico, abierto, siempre en formación, en evolución perenne, necesariamente desintegrativo, para poder integrar elementos de variados orígenes y caracteres, y todo ello - incluido el propio proceso a lo largo del cual se produce esta negación dialéctica-constituye su esencia o carácter nacional.

Diana Iznaga (1989: 52)

[...] la escritura migrante obliga a un cuestionamiento de las bases mismas de la noción de literatura quebequense (nacional o transcultural), de su naturaleza (mestizada o no) y de sus relaciones con las demás literaturas.

Clément Moisan (2001: 328)

La progresiva incorporación de las minorías étnicas a lo largo de la segunda mitad del siglo XX ha conducido a la sociedad quebequense a revisar los elementos que definían un perfil identitario defendido con tanto empeño y pasión no sólo hasta el parteaguas de la Revolución Tranquila, sino todavía hasta años recientes. La creciente presencia de esos "quebequenses llegados de otra parte" ha incidido inevitablemente en las percepciones sociales en por lo menos tres direcciones que, por razones obvias, modifican el paisaje literario de la provincia.

En primer término, ese pueblo que se concebía culturalmente "monolítico" ve el desmoronamiento irreversible de tal convicción para dejar paso a una sociedad multiétnica y multicultural.

En segundo lugar, y como consecuencia de lo anterior, se produce una ruptura de las fronteras del universo mental quebequense ya que, durante 
mucho tiempo, la sociedad se había conformado con hurgar únicamente en aquello que consideraba ser su especificidad.

Por último, los nuevos horizontes vislumbrados a través de las alteridades recientemente insertas en el tejido social de adopción propiciaron y alentaron, entre los quebequenses "de pura cepa", la necesidad de abrirse a otros universos, geográficos, culturales e imaginarios, más allá de sus propias fronteras nacionales, lingüísticas y mentales.

Las letras quebequenses contemporáneas ofrecen pues cada vez más ejemplos de esta evolución en la percepción de sí mismos y del otro, o los otros, no sólo porque el paisaje literario ostenta como propias una diversidad de figuras que encarnan imaginarios pertenecientes a otros universos culturales, sino también porque las plumas emergidas de la tradición local vuelven cada vez más frecuentemente su mirada hacia el exterior.

Conscientes de que en unas cuantas páginas resulta imposible ahondar lo suficiente en las tres líneas apuntadas anteriormente, centraremos nuestros comentarios y reflexiones sobre todo en torno del fenómeno de la llamada literatura "neoquebequense". Más adelante nos detendremos en este particular.

\section{Revisión de algunos mitos}

Comencemos pues por recordar que la dinámica migratoria que caracterizó al primer mundo, resultante del desmantelamiento de los imperios coloniales europeos y de los abismos económicos entre norte y sur, sobre todo durante la segunda mitad del siglo pasado, modificó sensiblemente los perfiles socioculturales de varios países desarrollados, entre los que incluimos desde luego a Canadá. La política canadiense de puertas abiertas, en este sentido compartida por el gobierno quebequense, ha dado lugar al asentamiento de minorías culturales de diversa procedencia cuya paulatina inserción en el tejido social ha ido modificando las premisas en que se sustentaba la conciencia identitaria de Quebec.

Sin detenernos ahora en los orígenes históricos del establecimiento de los colonos franceses en América, uno de los rasgos que recorre cada uno de los momentos clave del devenir de este pueblo fue la reivindicación de una identidad configurada por la lengua, la religión y la cultura; este patrimonio imprimía a la comunidad una cierta homogeneidad que le permitía resistir a la asimilación dentro de un entorno dominante esencialmente anglosajón. La bandera de la especificidad cultural fue enarbo- 
lada a lo largo de varios siglos y la preocupación prioritaria de este pueblo fue preservarla como sustento y orgullo de la conciencia nacional.

Investigaciones más recientes, como las emprendidas por especialistas entre los que destaca Gérard Bouchard, han permitido revisar los presupuestos anteriores y puntualizar detalles que obligan a enderezar viejas percepciones, un tanto dogmáticas, acerca de la más bien mítica homogeneidad cultural de la sociedad quebequense. Por lo pronto, Bouchard sostiene que la francofonía quebequense "se constituyó en torno de un componente principal, herencia de sus orígenes franceses, pero que se alimentó con otros muchos aportes gracias al contacto con diversas comunidades étnicas y al paso de su propia experiencia colectiva en el continente norteamericano" (1993a: 3) y esto desde el siglo XVII. En realidad, esa visión monolítica de una cultura homogénea fue producto de un proyecto más o menos deliberado de las elites francocanadienses (burguesía y clero que, por otro lado, eran los aliados del poder colonial inglés) cuyo discurso tenía como eje principal la "diferencia cultural" con respecto a sus vecinos. Este tema de la "diferencia", léase especificidad emanada de la lengua, la religión y las tradiciones culturales, fue un caballito de batalla en la literatura décimonónica que, justamente, sucumbía al influjo de las corrientes literarias europeas tan imbuidas de la convicción en la existencia de un alma nacional propia de cada pueblo.

Uno de los factores decisivos en esta reciente revisión de las percepciones acerca de la cultura y de la sociedad quebequenses ha sido la sustitución de ciertas categorías de análisis tomadas de disciplinas como la sociología, la antropología, la historia, la arqueología de la cultura, el psicoanálisis, por sólo citar algunas. ${ }^{1} \mathrm{Y}$ desde la perspectiva que nos atañe más directamente, la literatura ha jugado también un papel capital no sólo en tanto que refleja la evolución de tales mutaciones, sino porque a su vez incide en la imagen que la sociedad tiene de sí misma. Ya desde las últimas décadas del siglo pasado, esa imagen era a todas luces la de una sociedad culturalmente heterogénea. Lo que quedaba por aceptar como un hecho consumado era la impronta palpable que las presencias alógenas habían impreso en el perfil de la sociedad receptora.

Una vez asentadas las ganancias sociales de los cambios generados durante las décadas de los sesenta y los setenta del siglo XX, el rasgo más emblemático de este parteaguas fue la adopción generalizada de gentili-

\footnotetext{
1 Pensemos en nociones como "cultura popular" vs. "cultura" (como patrimonio de la elite), la noción de interacción, de hibridez, de alteridad, de imaginario cultural, de culturas periféricas o marginales, conciencia identitaria, dinámica colectiva, etcétera.
} 
cio "quebequense" para identificar todo: instituciones sociales, creaciones artísticas y culturales, proyectos locales, bienes reales y simbóli$\cos$, todo sería en lo sucesivo quebequense, dejando atrás la etiqueta que remitía a otras dos instancias de las que la provincia pretendía deslindarse: Canadá y Francia. El viejo conflicto de una identidad frágil y amenazada quedaba en apariencia saldado; al impedir cualquier equívoco mediante esa etiqueta, las fronteras frente al/los otro(s) parecían quedar claramente marcadas. Sólo que el entorno social no nada más dentro de la provincia, sino a lo largo y ancho de la federación, ofrecía un panorama por demás abigarrado desde el punto de vista sociocultural. ${ }^{2}$ La apuesta identitaria se plantea ahora desde otro ángulo pues la presencia inocultable de otras marcas culturales, de imaginarios exóticos, de referencias ajenas al entorno familiar impone la adopción de otros criterios, más variados y complejos.

Las revisiones históricas arriba evocadas revelan una serie de datos útiles para entender el proceso que desembocó en esta realidad pluricultural y que por lo mismo puso en tela de juicio el mito de la homogeneidad cultural.

\section{La promesa del Nuevo Mundo y sus consecuencias}

El flujo de inmigrantes a la porción norte del continente americano fue constante desde su colonización por ingleses y franceses, sobre todo a partir del siglo XVII. Tanto los actuales Estados Unidos como Canadá fueron poblados casi esencialmente por inmigrantes ya que su política desplazó o eliminó, o en el mejor de los casos, ignoró a los grupos autóctonos. En el caso concreto de Canadá, el movimiento migratorio en cuanto a las zonas de procedencia de dichos flujos, permaneció sustancialmente igual hasta poco después de mediados del siglo XIX. A raíz de la creación de la Confederación canadiense en 1867, empieza a notarse el arribo de extranjeros provenientes de otros países que no eran ni Francia ni Inglaterra.

Entre 1871 y 1901 el incremento es de $8 \%$ a $10 \%$; hasta 1914 se registran tres millones más de inmigrantes que, en general, proceden tanto del occidente como del centro de Europa. Hacia esas fechas y durante la

${ }^{2}$ Aunque el fenómeno se haya acentuado en épocas más recientes, este proceso se registra desde mucho tiempo atrás con los vecinos del sur, es decir los Estados Unidos, y en la vieja Europa, merced, entre otros factores, a la movilidad demográfica resultado de la globalización. 
entre-guerra, en que el movimiento incluso decreció por efecto de la crisis económica, se registró una tendencia a la emigración; por su parte los inmigrados se instalan sobre todo en las zonas industriales tanto de Ontario como de Quebec, particularmente en Toronto y en Montreal.

Durante la entre-guerra el ritmo migratorio se reanuda y aumenta, pero sobre todo se diversifica después de la Segunda guerra. Las zonas expulsoras de migrantes se extienden a Asia, África, América latina y el Caribe. Dato curioso, entre 1902 y 1980 , el porcentaje de inmigrados franceses a Quebec apenas si creció de un $2 \%$ a un $4 \%$. Viendo en conjunto el reparto de los diferentes grupos poblacionales, es de notarse la importancia que los recién llegados empiezan a cobrar en las grandes concentraciones urbanas, como ilustra el caso tan significativo de la región de Toronto donde en 1971 la población de origen no británico alcanzaba el $43 \%$ y actualmente es superior a la mitad. Por su parte, la aglomeración urbana de Montreal registra en el mismo momento un $20 \%$ de no franceses y no británicos, porcentaje que hoy día alcanza el $30 \%$.

En este marco general del fenómeno global de migración hacia Canadá, nos referiremos específicamente al caso de Quebec para contextualizar el tema que nos ocupa, es decir la emergencia y los efectos que la literatura escrita por escritores pertenecientes a las llamadas minorías étnicas o comunidades culturales han generado en el paisaje literario de la provincia.

Un primer detalle que no puede ser pasado por alto es que el incremento y el reparto de estos flujos poblaciones han originado la necesidad de reglamentar los modos de inserción de los extranjeros en virtud de que, por ejemplo y hasta no hace mucho tiempo, en la provincia de Quebec los recién llegados recurrían más fácilmente a las instituciones educativas y otros servicios anglófonos por considerar que el conocimiento del inglés abre puertas en sectores y espacios más amplios y diversificados. Para frenar esta tendencia que apuntaba a una seria disminución de la población francoparlante en la provincia, el gobierno quebequense adoptó en 1971 la controvertida Ley 101 que impone a los inmigrantes la inscripción de sus hijos en escuelas de habla francesa. Si tomamos en cuenta que el $82 \%$ de los inmigrados instalados en la provincia de Quebec vive en la región de Montreal, apreciaremos el alcance de dichas medidas reglamentarias. ${ }^{3}$

${ }^{3}$ En 1991 la Comisión escolar de Montreal preveía que para el año 2000 más del $50 \%$ de los alumnos serian de procedencia no francófona. En algunas zonas urbanas existen escuelas cuya población de origen extranjero alcanza el $90 \%$ y más (cf. Moisan: 24). 
Por otra parte, la situación arriba descrita permite entender que, sobre la tela de fondo de las dos lenguas dominantes y oficiales, en las grandes aglomeraciones urbanas el mosaico compuesto por las diversas minorías étnicas conlleva el uso de otras tantas lenguas y la manifestación de igual cantidad de tradiciones culturales. Esta evidencia condujo, por lo demás, a la adopción de políticas federales y provinciales que contemplan la composición multicultural de la población. ${ }^{4}$ Dado el carácter complejo y controvertido de este aspecto de la realidad canadiense, así como la especificidad del fenómeno literario que nos ocupa, no entraremos en el detalle de los aciertos, fallas o retos de la política oficial en esta materia, sin que por ello renunciemos a apuntar algunas de sus incidencias en el ámbito de las letras.

Ahora bien, tomando en cuenta el contexto arriba esbozado, cabría preguntarse: ¿cuáles son los retos que entraña este paisaje étnico, lingüístico y cultural?

Para empezar, el relativo a la identidad que, según los grupos, difiere en matices e intensidad. En efecto, conviene tener presente que el problema de las reivindicaciones identitarias no es exclusivo de Canadá. Durante las últimas décadas, prácticamente en todas las latitudes del planeta la vivencia de la identidad ha dado lugar a diferentes tipos de manifestaciones que, en ocasiones, se han distinguido por la violencia, la irracionalidad y el fanatismo. Pero, una vez más, nuestros comentarios se limitarán al caso quebequense en el que para empezar podemos distinguir al menos cuatro grupos sensibles al problema identitario.

En primer término, habría que tomar en consideración a los grupos amerindios que, sobre todo en las últimas décadas, han recurrido a diferentes estrategias para reivindicar sus derechos y especificidad. En segundo lugar hay que mencionar a la minoría de origen inglés, perteneciente a lo que se ha llamado los grupos fundadores y que está asentada en la provincia casi desde la misma época que los colonizadores franceses. En tercer término consideraremos, casi en el mismo plano que el grupo anterior, a los quebequenses que a todo lo largo de su historia han vivido el problema de la identidad como vertebral. Y por último, mencionaremos el caso de los alófonos, es decir, todos los grupos minoritarios cuyos orígenes étnicos, lingüísticos y culturales son diferentes a los de la sociedad receptora a los que nos referimos en estas páginas. $(2000)$.

${ }^{4}$ Legislaciones de 1971 y 1988; ver Monique Lebrun (1994: 91) y Michel Plourde 


\section{El oficio de escribir}

En el terreno concreto de la literatura, una vez instalado en suelo canadiense, el extranjero que siente la necesidad de dedicarse a las letras puede optar por una de las dos lenguas oficiales y, según los casos, tomar o no en cuenta las "reglas" del medio en lo que concierne a tendencias, temas, géneros, formas de escritura e inscribirse en la dinámica sociocultural propia de esta actividad y de acuerdo con su nuevo contexto. En este sentido, la obra literaria se presenta no sólo como una suerte de reflejo de una realidad a veces construida con imágenes estereotipadas, sino como una "mirada" especular de sí mismo y del otro, gracias a la cual es posible observar lo conocido y lo que resulta ajeno, lo inmediato y lo lejano o imaginado. La escritura literaria se convierte entonces en uno de los espacios donde mejor puede estudiarse el fenómeno del mestizaje cultural, muchas veces a través de la hibridación de los códigos lingüísticos, de la incorporación de nuevas temáticas que, según las posiciones adoptadas, llegan a ensanchar y a complementar el horizonte local. Dadas estas condiciones, ya no es posible estudiar ningún fenómeno social o cultural sin tomar en cuenta, por un lado, las aportaciones de los inmigrantes $\mathrm{y}$, por el otro, las interrelaciones entre los diversos grupos que integran dicha sociedad.

Clément Moisan y Renate Hildebrand (2001) en un acucioso estudio sobre la participación de los inmigrantes en la historia literaria de Quebec, identifican cuatro grandes fases de esta presencia y, en cada una, subrayan los modos de inserción o adopción que los escritores extranjeros han practicado frente a las corrientes, movimientos y códigos locales. Su propuesta pone en primer lugar lo que denominan la fase de lo "unicultural", cuando los recién llegados unen su voz a la de los lugareños, sin manifestar discordancias. Viene después otra que se distingue por lo "pluricultural", donde sin forzosamente mezclarse, las diferentes voces forman un conjunto polifónico. En tercer término vendría la llamada "intercultural", en la que unas frente a otras, las voces empiezan a poner de manifiesto los procesos de transformación que mutuamente registran por el contacto al que están expuestas para, por último, desembocar en la fase "transcultural" que correspondería al momento actual en el que las corrientes se atraviesan unas a otras dejando más o menos al descubierto los modos en que se vive la alteridad. Si tomamos en cuenta la diversidad de perfiles étnicos, esta otredad se multiplica hasta formar un mosaico.

En todo caso, que los inmigrantes recién llegados o avecindados desde varias generaciones atrás se sintieran integrados o no a su nuevo en- 
torno, a raíz de las legislaciones federales de 1973 y 1988 sobre el multiculturalismo se hizo más imperiosa la necesidad de aceptar oficialmente que las minorías étnicas no sólo ocupaban un lugar en el tablero social, sino que de diversas maneras contribuían a su transformación y que, en especial en el terreno de las artes y otras disciplinas intelectuales, incluyendo a la literatura, sus aportaciones no podían ser soslayadas al estudiar la evolución de las nuevas creaciones.

\section{Buscando etiquetas}

La presencia de una literatura emergida en el seno de las comunidades culturales pone de manifiesto la profunda y sustancial transformación de la cartografia literaria quebequense.

Pero para justificar una afirmación de esta índole, conviene plantearse previamente algunas interrogantes inherentes a la identidad de los autores incluidos en estas minorías. Sin agotar la infinidad de aspectos que entraña esta cuestión, cabría empezar por los que surgen de manera más obvia y recurrente en cuanto se trata de circunscribir el referente a que remite la denominación de "literatura de comunidades culturales, étnicas, inmigrantes... o incluso neoquebequenses" (Harel 2002: 439) que vemos aparecer cada vez con mayor frecuencia tanto en la crítica periodística como en la crítica universitaria, en la teoría y, por supuesto, en las clasificaciones que editoriales, manuales y antologías adoptan para identificar estas producciones dentro del corpus más vasto de lo que se acepta como literatura quebequense y todavía más ampliamente literaturas francófonas.

En efecto, $¿$ cuáles son los criterios en los que se apoya tal identificación? ¿El origen geográfico, el lugar de nacimiento, la lengua materna, la relación entre ésta y la de la sociedad de adopción, la percepción y el modo de inserción en ésta? Podríamos admitir que estos criterios figuran entre los más socorridos, pero igual cabría preguntarse si las clasificaciones que de ellos emanan no son también el resultado de los modos de intervención de las diversas instancias de la institución literaria ${ }^{5}$ así como del aparato político encargado de asignar a estos nuevos actores del quehacer cultural un lugar en el tejido social.

El establecimiento de categorías a partir de criterios etnoculturales, además de traducir el reconocimiento de una situación de hecho, supone

${ }^{5}$ En el sentido que el investigador belga Jacques Dubois (1978) confiere a esta expresión y que ya es compartido por la mayoría de los medios literarios. 
igualmente la aceptación de la existencia de una serie de factores alógenos que cruzan y atraviesan el tejido social y que, por lo mismo, trastornan el viejo mito de los quebequenses de constituir una sociedad homogénea. Ya antes señalamos que Gérard Bouchard y otros historiadores han analizado ampliamente la cuestión y subrayado cómo y por qué tal creencia no reflejaba con fidelidad la realidad sino que era una construcción de las elites preocupadas por mantener la cohesión de una sociedad sobre la que ejercían sus privilegios. Durante mucho tiempo se combatió cualquier contacto con el Otro, así como los intentos de apertura hacia el exterior (1996b: 13-15).

Uno de los aspectos más notorios en el horizonte literario de las últimas décadas es precisamente el desplazamiento en el discurso social, que estrechó aún más sus vínculos con el discurso literario, de la temática de la "unidad de una nación homogénea" para atraer al primer plano un abanico de discursos sobre la hibridación, el mestizaje, la otredad múltiple, el exilio, en pocas palabras un discurso de la heterogeneidad.

El efecto producido por la presencia de esas otras voces en el proceso discursivo de la creación literaria local tiene una contrapartida en el trabajo de la lengua por parte de los nuevos interlocutores pues, aunque éstos adopten el nuevo código como medio de expresión, la lengua materna sigue habitándolos y, a pesar de su desterritorialización, es posible discernir, más o menos abiertamente, las huellas de este proceso en el nuevo tejido discursivo. Lo anterior se traduce en ocasiones en desviaciones con respecto a la norma que, para algunos, constituyen efectos de exotismo.

Desde otra perspectiva, tal parece que al asociar un tanto superficialmente identidad y territorialidad, la delimitación del concepto de minorías culturales resulta difícil y que, en esa medida, el discurso oficial buscaría apuntar de manera retórica a un antagonismo entre la pluralidad cultural y el ombliguismo identitario, como para hacer contrapeso a este último. En todo caso, la literatura surgida en el seno de tales minorías es la que se singulariza por su pertenencia a una comunidad o en la intersección de varias. No está por demás señalar que los testimonios de los concernidos abarcan un espectro muy amplio, desde aquellos que reivindican esa diferencia y exhiben conscientemente su especificidad, hasta los que denuncian las trampas de la política multiculturalista por traducirse, a final de cuentas, en una suerte de ghettoización ${ }^{6}$ que favorece la fijación de las diferencias étnicas grupales en vez de prestar aten-

${ }^{6}$ El término es empleado por Neil Bissoondath en Le Marché aux Illusions: la méprise du multiculturalisme. Montreal, Boréal, 1995, p. 222. 
ción a la singularidad de los individuos y de alentar su integración mediante la adaptación mutua de los diversos grupos que interactúan.

\section{El multiculturalismo en tela de juicio}

En esta dialéctica social entre creaciones artísticas y estructuras institucionales y legales que las traducen o enmarcan, las políticas oficiales en materia de multiculturalismo han dado lugar, según algunos intelectuales, más que a una integración de las llamadas minorías - entre las cuales las llamadas "visibles" resultan más afectadas-7 a una compartimentación en especies de "ghettos" que las condena a alimentar ligas ilusorias con el país de origen. Líneas atrás señalamos cómo el escritor Neil Bissoondath (1995) desmenuzó con gran agudeza y no poca objetividad las trampas de la política multiculturalista canadiense, cuyos efectos perversos en realidad se traducen en que el supuesto respeto a las "minorias étnicas" implica la existencia, en el otro lado del tablero social, de la verdadera "mayoría" a la que, a fin de cuentas, nunca podrán pertenecer por entero toda vez que se les ha fomentado la importancia de preservar sus rasgos culturales específicos. Hasta un cierto momento, y en algunos sectores, han surgido voces que parecen, detrás la política confesa de respeto a las minorías, no haber abandonado las antiguas reivindicaciones identitarias encubridoras de la incapacidad para asimilar la diversidad característica de su composición actual.

La complejidad del problema hace que la discusión en torno al concepto de etnicidad subyacente a cualquiera de las manifestaciones culturales que se quiera analizar desde esta perspectiva, se torne o reductora o extrema. Tal es el caso de las reacciones desatadas por la ya evocada Ley 101 que en materia lingüística impone, en Quebec, la obligación de que los hijos de los inmigrados asistan a las escuelas francófonas con la intención de que, para combatir la tendencia a la anglicización, la lengua oficial de la provincia sea en efecto el denominador común y código de comunicación e intercambio entre los diferentes grupos sociales. Lo que en realidad debería prevalecer, tanto por parte de las mayorías como de las diversas minorías, es la convicción de que, sin atentar contra el respeto a las diferencias, todos y cada uno tienen que participar en la construcción de lo que Michel Morin y Claude Bertrand denominan el territorio imaginario de la cultura (1979).

\footnotetext{
${ }^{7}$ Nótese el dejo racista de tal clasificación; $c f$. Jean Lafontant (1994: 47-58).
} 
Lo cierto es que por su participación activa en diversos sectores, dichos grupos modifican el tejido social así como el imaginario de toda la colectividad metropolitana. Y en el ámbito específico de las letras, aceptar esta situación de facto equivale a reconocer que, bajo otras modalidades y con una apuesta ciertamente diferente, la literatura y el problema de la identidad vuelven a encontrarse en el paisaje cultural quebequense.

Por otra parte, sin entrar en detalles respecto a las diversas formulaciones y manifestaciones que el problema de la identidad ha asumido a lo largo de la historia del pueblo quebequense, conviene recordar por lo menos que uno de los momentos clave de este proceso evolutivo, es decir de la reivindicación de la especificidad lingüística y cultural, es la década de los sesenta de la Revolución Tranquila que ya evocamos al principio. La simple adopción de un gentilicio que no remitiera a referentes susceptibles de ambigüedad (lo canadiense que incluye lo anglófono, y lo francés que asocia con la antigua metrópoli), consagró un parteaguas en la autopercepción de la comunidad francoparlante de la provincia de Quebec. El momento en sí mismo es clave y en el tema que nos ocupa lo es doblemente pues, dado el contexto internacional de la segunda posguerra, coincide, como ya dijimos, con un importante flujo de inmigrantes de diversas procedencias. Así, mientras los quebequenses están estrenando en cierto modo una conciencia identitaria más segura de sí misma, los recién llegados e incluso los extranjeros ya asentados con anterioridad en suelo canadiense, también, pero a su modo, experimentan la necesidad de revisar los criterios que los definen según sus raíces, independientemente de que pretendan o no reivindicar abiertamente su diferencia.

Tomando en cuenta lo anterior, lo menos que podemos constatar es la ambigüedad que entraña el planteamiento, ya que si partimos de la base de que la literatura quebequense nace y se consolida en un espacio oficialmente bilingüe, la reivindicación de su carácter "nacional" no puede menos que remitir a un referente cuyo estatus es ambiguo, ya que su espacio simbólico no es Canadá en su totalidad, ni la provincia constituye por sí misma una nación. Obviaremos, por complejo, el viejo debate acerca de dicha noción.

Una segunda ambigüedad se refiere a la interdependencia de la literatura quebequense frente a las llamadas literaturas francófonas con las que comparte, además de la lengua, algunos puntos comunes, ${ }^{8}$ pero frente a las que ostenta serias diferencias, como por ejemplo la vivencia de la

${ }^{8}$ Que, por cierto, también son identificables en otras literaturas emergentes, sin tomar en cuenta la lengua de expresión. 
lengua francesa como la lengua del Otro, como la lengua del antiguo poder colonizador. Cabe entonces preguntarse si el empleo de un código lingüístico compartido justifica la pertenencia a un bloque por demás heterogéneo y diverso y en el que, a final de cuentas, cada literatura ocupa una posición marginal de acuerdo con el centro simbólico que corresponde a Francia.

En fin, dado que las aportaciones de la inmigración han modificado a todas luces el paisaje cultural de las últimas décadas, ¿cómo clasificar entonces las obras de estos nuevos actores sociales? Aunque líneas atrás señalamos la falta de acuerdo sobre este punto, insistimos en la necesidad de si conviene adoptar la etiqueta de literatura producida por las minorías culturales o étnicas, o bien "literatura neoquebequense" empleada por algunos, pero no forzosamente aceptada por todos, o bien admitir sin rodeos ni mayor trámite que se trata simple y sencillamente de creaciones ya integradas a la cultura quebequense a secas. Cualquiera que sea la opción que se tome (todas pueden ser válidas o igualmente desechables), el verdadero fondo del asunto y lo que realmente cuenta es que en la inmensa mayoría de los casos, de cerca o de lejos y con diversos tratamientos, sale a relucir la cuestión de la identidad.

\section{Las instancias de legitimación}

Para empezar, la lengua de escritura (ya sea materna o extranjera) entraña, en su empleo, una serie de actitudes dictadas por un imaginario que varía de acuerdo con los individuos y las culturas de origen. Dijimos anteriormente que los inmigrantes se ven obligados a aprender al menos una de las dos lenguas oficiales del país y, al momento de optar por una de ellas como lengua de escritura, es casi automático que adopten las reglas del juego vigentes en la institución literaria correspondiente. Ahora bien, si admitimos que, en este sentido, la literatura quebequense puede considerarse como autónoma puesto que ha logrado consolidar las correspondientes instancias de reconocimiento y legitimación, habría que discernir en qué consisten las aportaciones de los escritores néoquebequenses a su perfil actual, pues resulta incuestionable que uno de los rasgos distintivos de su imagen hacia el exterior es el del multiculturalismo.

¿En qué consisten pues las aportaciones de los llamados escritores néoquebequenses? Más arriba mencionamos que el problema de la identidad acercaba a unos y otros, así que sería en las diferencias que los separan donde detectaríamos la manera en que los de origen extranjero 
vinieron a transformar la producción local. Los estudiosos señalan que las escrituras inmigrantes se transforman en migrantes cuando, tras haberse centrado en el pasado y el presente de la cultura tanto materna como de la sociedad de adopción, se orientan más hacia un futuro ocupado por el otro, a través y con el que pueden llegar a fundirse.

Si partimos de la base de que toda cultura en contacto con otra(s), al tiempo que recibe elementos hasta entonces ajenos a lo que se considera su especificidad, hace a su vez nuevos aportes que la(s) otra(s) cultura(s) desconocía(n). Para apoyar lo anterior sobran los ejemplos a todo lo largo del tiempo y del espacio, pues la historia de las civilizaciones no es otra cosa sino el resultado de dichos intercambios. No son pocos los intelectuales 9 que han descrito el fenómeno más o menos en los mismos términos empleados por Arturo Uslar-Pietri, quien nos dice que:

[...] la historia de las civilizaciones es la historia de los encuentros. Si algún pueblo hubiera podido permanecer indefinidamente aislado y encerrado en su tierra original, hubiera quedado en una suerte de prehistoria congelada. Fueron los grandes encuentros de pueblos diferentes por los más variados motivos los que han ocasionado los cambios, los avances creadores, los difíciles acomodamientos, las nuevas combinaciones, de los cuales ha surgido el proceso histórico de las civilizaciones (1969: 10-11).

Hoy día, en diferentes escalas y acaso con otros matices, la experiencia sigue repitiéndose debido a la creciente movilidad demográfica que se registra de manera más acentuada hacia los países del primer mundo, como es el caso de Canadá. Y, ciñéndonos a nuestro tema, lo que nos interesa es identificar los modos de ubicación y de inserción adoptados por los escritores inmigrantes dentro del sistema que define a la institución literaria de Quebec. Régine Robin, nacida en Francia pero de origen judío polaco y establecida en Montreal desde los años setenta, identifica tres posiciones posibles según el origen étnico del escritor, según la temática $o$, finalmente, de acuerdo con el tipo de escritura, sin que ninguno de los tres ejes lo sujete a reglas o leyes precisas. Partiendo de esta base, algunos escritores se inclinarán por centrarse en la representación de su cultura de origen; otros buscarán la fusión en la cultura del Otro, o más aún, habrá aquellos que persigan situarse por encima de ambas culturas,

${ }^{9}$ Ver, entre otros, Francois Laplantine y Alexis Nouss. 1997. Le Métissage. París. Flammarion. 
o bien proceder a una suerte de hibridación, que ya en otros contextos ha sido calificada de "transculturación" ${ }^{10}$ En realidad resulta difícil establecer linderos claros entre las tres posiciones pues, como dice Robin, citada por Moisan (2001: 55): "todo equivale a hurgar dentro de sí y a cavar en la escritura una posición de extranjero, de extrañeza, de inquietante extrañeza, situación inherente a toda forma de escritura en cuanto ésta abandona posiciones de certeza identitaria, en cuanto la identidad va dejando de ser compacta y se problematiza". Como quiera que sea, en las dos primeras categorías se observa la tendencia a abrevar en el pasado o a centrarse en los retos que impone la realidad presente, pero todavía no se concede el suficiente espacio a la proyección hacia el futuro; ése será más bien el rasgo distintivo de la fase transcultural arriba evocada.

Como decíamos antes, al ofrecernos la posibilidad de aprehender la vivencia de la identidad, la escritura de los inmigrantes nos permite observar cómo éstos se incorporan a la literatura quebequense, la modifican $\mathrm{y}$, en el proceso, cómo ambos grupos se enriquecen. Podría afirmarse que, de manera casi definitiva, la producción literaria quebequense se caracteriza por las transferencias y redes de intertextualidad que se tejen entre los diferentes grupos del conjunto.

Antes de alcanzar el nivel de transculturación en el que los rasgos originales de los grupos o individuos confrontados se desdibujan de alguna manera para dar lugar a un nuevo perfil, la fase anterior que arriba denominamos como "intercultural" puede caracterizarse, en una perspectiva comparatista muy productiva, por dos modos de relación: ya sea como choque entre culturas o individuos, cuyos resultados subrayan las diferencias, o bien como la confrontación que atiende a destacar las similitudes y puntos de encuentro entre los términos comparados. De cualquier manera, así se enfatizara sólo alguno de los dos acercamientos, el conjunto requiere una permanente redefinición en virtud de los cambios que van produciéndose en los elementos confrontados.

Tras el análisis del corpus constituido tanto por las obras de los escritores neoquebequenses como de los quebequenses de "pura cepa", es posible destacar que el papel que juegan unos y otros es el de mediadores, intérpretes y críticos del "entre-deux", es decir de esa zona donde las fronteras identitarias se vuelven porosas y en ambos lados es perceptible la modificación de los marcos de referencia. En este sentido, los reajustes que la institución literaria quebequense ha tenido que operar ponen de

${ }^{10}$ Cf. Diana Iznaga. 1989. Transculturación en Fernando Ortiz, La Habana, Editorial de Ciencias Sociales. 
manifiesto que "las obras neoquebequenses ya no son sólo una parte del sistema sino un componente necesario de la literatura quebequense, cuyo rostro no sería el mismo sin esta aportación que le ha conferido, por así decir, "otra" naturaleza" (Moisan, 2001: 209).

Además de la revisión identitaria a la que la incorporación de las minorías étnicas condujo a la sociedad quebequense y, en particular, a los intelectuales y artistas, uno de los efectos de esta presencia fue, ya se dijo, el de la apertura hacia el mundo. Este giro se traduce por cierto, en un ensanchamiento de los horizontes imaginarios y mentales de un pueblo que durante tanto tiempo se mantuvo con la mirada puesta en su propio espacio, en su propia problemática y en la preocupación por preservar lo que consideraba su especificidad. La interacción con nuevos actores sociales suscitó los flujos de ida y vuelta que por fuerza desembocaron, como ya vimos, en procesos de transculturación. En el espacio más concreto de las letras es posible constatar cómo la progresiva inserción de las plumas neoquebequenses en los marcos institucionales (editorial, universitario, instancias críticas, jurados) avala y legitima su pertenencia al sistema literario local.

\section{Intertextualidad + transculturalidad $=$ transtextualidad}

La incorporación antes descrita ofrece otro ángulo de interpretación: evocar la noción de intertextualidad al referirnos al corpus analizado ${ }^{11}$ equivale a aceptar su condición de transculturalidad en tanto que expresión de la manera como las obras se abren paso recíprocamente en el entramado de unas y otras, ya sea porque coinciden, se complementan o porque se hacen eco. Desde la perspectiva de la sociocrítica, se hablaría de "inscripción de un texto en otro" o, en relación con un texto principal, a los demás se les reconocería como co-textos. Así, esta intertextualidad sinónimo de transculturalidad, podría ser denominada como transtextualidad en el sentido en que las transferencias se efectúan entre los escritos producidos por los quebequenses nativos y los creados por los provenientes del extranjero, pero en los que se identifica un cierto espacio temático, discursivo o imaginario creado conjuntamente y por lo mismo compartido.

El caso de Monique Proulx, en Les Aurores montréales (1996) es uno de los más representativos de esta dinámica transferencial. A este respec-

\footnotetext{
11 Es decir, las obras tanto autores neoquebequenses como algunas de los escritores originarios de la provincia desde muchas generaciones atrás.
} 
to, Moisan y Hildebrand nos dicen que "la unidad [de esta obra descansa] en el lugar y el medio de la metrópoli en la que son puestos en escena escritores y escrituras migrantes" (269). Los relatos son, en sí mismos, espacios de paso, de intercambios y transferencias en muy diversos niveles: de una cultura a otra, de un barrio a otro, de una lengua a otra. De este abigarrado entramado de vías posibles para comunicar con el otro, lo que se desprende no es otro sentimiento sino el de la imperiosa necesidad de buscar todas las fórmulas posibles de relación, de comunicación, de contacto con el otro; sólo en ese movimiento que empuja al encuentro de la alteridad será imaginable adoptar, adaptarse y familiarizarse con la diferencia, pues no hay que olvidar que entre la identidad y la alteridad existe, por encima de un recelo inicial e irracional, una inevitable atracción.

\section{La consagración por encima del debate}

Sin remontar hasta épocas anteriores a la Revolución tranquila, en la década de los setenta es perfectamente clara la iniciativa, por parte de los escritores inmigrantes, de inscribirse en la historia y en la dinámica de las actividades literarias locales. Una de las puertas por las que se hace sensible esta presencia es la de la participación en el debate que, en revistas, periódicos y otras publicaciones, pone de manifiesto posiciones frente a asuntos de actualidad que los involucran de una manera o de otra. Los espacios editoriales constituyen otra vía ya que las instituciones locales abren progresivamente sus puertas a estos nuevos actores que, por otro lado, a veces buscan crear sus propios órganos editoriales a través de revistas más o menos especializadas en las problemáticas que les atañen directamente y para facilitar un foro de expresión a las nuevas voces venidas de otra parte.

Ante una realidad que se impone por sí misma, otras instancias de la institución literaria quebequense acaban por alinearse y otorgar su reconocimiento, como es el caso del otorgamiento de premios y distinciones, así como de la inclusión de autores neoquebequenses en los programas universitarios y manuales escolares. Este proceso de legitimación fue resultado, en buena medida, de la labor que desde sus inicios realizó primero la crítica periodística, luego la especializada practicada por los universitarios. Y poco a poco, la familiaridad en los espacios literarios y artísticos, entre creadores y estudiosos quebequenses e inmigrantes, ha ido configurando una comunidad que comparte a menudo las mismas expectativas, las mismas necesidades, las mismas inquietudes, pero so- 
bre todo, el deseo de no encerrarse dentro de fronteras mentales y simbólicas que impiden el acercamiento y el entendimiento con el otro. Esto, la apertura hacia el exterior, se convierte, ya se dijo, en un rasgo distintivo de las letras quebequenses en general y una de sus cartas de presentación en el extranjero.

Otro factor responsable de esta evolución es la importancia de las antologías e historias literarias recientes que proceden a revisar tanto las periodizaciones como las jerarquizaciones a partir de otros criterios que incluyen nuevos nombres y géneros.

Los grupos universitarios de investigación, entre los que destacan el encabezado por Sherry Simon en la universidad Concordia, o en la UQAM el coordinado por Daniel Chartier que elabora el diccionario de escritores inmigrantes, o más aún investigadores que como Maximilien Laroche o Clément Moisan de la universidad Laval han contribuido a consolidar el estudio de las nuevas escrituras, son un claro testimonio de que el horizonte literario quebequense no sólo no puede prescindir de estas voces, sino que no puede explicarse sin tomar en cuenta su actual dimensión transcultural. Resulta indiscutible que al reconocer esta nueva realidad, la sociedad quebequense asume los cambios que se han generado en su seno y que en el espacio literario, concretamente, las aportaciones de los escritores neoquebequenses también han operado cambios en las tendencias del antiguo corpus considerado como nacional.

La querella suscitada en 1996 por la conferencia pronunciada por Monique Larue (1996) en la universidad de Montreal cristalizó en una serie de posiciones, extremas algunas, otras más ponderadas $y$, en todo caso, permitió revisar todos los presupuestos más o menos aceptados en torno a la distinción entre escritores de "pura cepa" e inmigrados. En el meollo de la polémica, lo que volvió a salir a relucir, con nuevos matices claro está, fue el viejo y recurrente problema de la identidad. Para algunos de los estudiosos en la materia, la actividad literaria en su diversidad no puede ser vista más que como la manifestación y la expresión de una sociedad pluriétnica, como lo es la realidad canadiense. No obstante, en tanto que síntoma de la situación actual, la polémica desatada por la conferencia de M. Larue permite prever más o menos la evolución futura de la literatura quebequense.

Muchos intelectuales y escritores han comprendido que con la mezcla de los diversos aportes culturales de los inmigrantes se desemboca en la construcción de un nuevo imaginario social y que por fuerza esto no hace sino enriquecer a la literatura quebequense. Así, por encima de la diversidad que las escrituras migrantes han venido a introducir en la literatura 
local considerada hasta no hace mucho como un corpus con ciertas características inherentes a la sociedad de la que emanaba y a la que pretendía reflejar, lo importante en el debate actual es que, como dice Réginald Martel en un artículo citado por Moisan (2001: 296-297):

[Aun] cuando un escritor escriba en el sentido opuesto de lo que hasta ahora habíamos considerado como propio de nuestra literatura, dicho escritor pertenece a nuestra literatura. Si no, eso significa que dejamos de estar dentro de la literatura. ¿Acaso no ha pesado lo suficiente sobre nuestros hombros el estar encerrados en la homogeneidad, en el monolitismo, en la etnicidad, en el colectivismo...?

El punto de partida de la reflexión de las últimas décadas por cuanto se refiere a la literatura quebequense era el de la pertenencia étnica y su correspondiente expresión mediante el discurso literario. $\mathrm{Y}$ es que, vista de este ángulo, la pertenencia étnica conllevaba la manifestación de la identidad cultural y, por fuerza, nadie, ni propios ni extraños, podía escapar a la emergencia, obvia y consciente, o velada y escamoteada, de ese sello en su creación literaria.

\section{A modo de conclusión}

La hipotética pero no menos deseable empresa compartida de construir un mismo "territorio imaginario de la cultura" es vislumbrable al menos en la escritura literaria que traduce la toma de conciencia de los procesos de inter y transculturalidad palpables, con diferentes grados de intensidad, a lo largo de las últimas décadas. Resulta innegable que la literatura quebequense actual lleva el sello de lo diverso, tanto a nivel temático como discursivo, y que cualquier proyecto nacional de construcción de una identidad debe partir de la premisa de la naturaleza multicultural que define a la sociedad en este inicio del tercer milenio.

Marco Micone, una de las voces más autorizadas en la materia, tanto por su condición de inmigrado como por el ejercicio de su oficio de escritor y crítico comprometido con esta realidad, lanza una suerte de reto a unos y otros, mayoría y minorías, a "solidarizarse con el fin de, paradójicamente, preservar el derecho a la diferencia dentro de un destino común". ${ }^{12}$ Para ello, lo primero que habría que revisar son los presupues-

${ }^{12}$ Citado por Moisan, p. 313. 
tos, implicaciones y consecuencias vinculados con las múltiples etiquetas acuñadas para designar la producción literaria de los escritores inmigrados. Hablar de literatura menor, minoritaria, étnica, neoquebequense o emergente es, a fin de cuentas, plantear desde el inicio y equivocadamente la noción que pretende remitir a un referente deseablemente bien circunscrito. Lo que no es el caso en la situación que nos ocupa frente a la cual, según algunos críticos como Bianca Zagolin, en vez de utilizar alguna de dichas etiquetas, lo sensato sería hablar de literatura a secas.

Lo sobresaliente de los últimos años es que la mayoría de los escritores inmigrantes tienden cada vez menos a enfrascarse en la problemática que cristalizó con la polémica desatada en torno a Monique Larue. Sin pretender hacer abstracción de su condición migratoria, lo que persiguen es alcanzar un equilibrio entre su pasado y su presente, pero siempre con la perspectiva de construir un futuro que comparten con muchos otros actores sociales. Se trata de un futuro en el que las tradiciones culturales de unos y otros se entrecruzan, tomando en cuenta que más allá de una identidad nacional, deben sentirse concernidos por una identidad cultural en perpetua mutación pues, en tanto que un modo de percibir la realidad en la interacción de los diferentes grupos sociales, ésta es el resultado, nunca acabado, de una construcción colectiva.

\section{Obras citadas}

AllARD, Jacques. 1992. "Fifty-Fifties: espaces socio-fictifs du réalisme spirituel". Le roman contemporain au Québec (1960-1985). Quebec: Archives des Lettres Canadiennes T. VIII Fides. 9-32.

ANCELOVICI, M. F. Dupuis-Déri. 1997. L'Archipel identitaire. Montreal: Boréal.

BEAUDOIN, Réjean. 1991. Le Roman québécois. Montreal: Boréal. BISSOONDATH, Neil. 1995. Le Marché aux illusions, La méprise du multiculturalisme. Montreal: Boréal.Liber.

BOUCHARD, Gérard. 1993a. "Une nation, deux cultures. Continuités et ruptures dans la pensée québécoise traditionnelle (1840-1960)". La construction d'une culture. Sainte-Foy: Universidad Laval. 3-47. . 1996b. Entre l'Ancien et le Nouveau Monde. Le Québec comme population neuve et culture fondatrice. Ottawa: Universidad de Ottawa. CASTIllo DURANTE, D. P. Imbert. 2003. L'interculturel au coeur des Amériques. Ottawa: Universidad de Ottawa / Universidad de Manitoba. 
DUBOIS, Jacques. 1978. L'Institution de la littérature. Introduction à une sociologie. Bruselas: Fernand Nathan / Éditons Labor.

GALLAYS, Francois. 1992. "Les 'jeunes' romanciers", Le roman contemporain au Québec (1960-1985). Quebec: Archives des Lettres Canadiennes T. VIII Fides. 485-500.

GaUvin, Lise. 2000. Langagement, L'écrivain et la langue Québec. Montreal: Boréal.

GREIF, Hans-Jürgen. 1997. "La littérature allophone au Québec. Écrire en terre d'accueil". Québec francais. Printemps. 61-65.

HAREL, Simon. 2002. "La littérature issue des communautés culturelles". Traité de la culture. Quebec: Les Éditions de L'IQRC, Universidad Laval. 439-456.

IZNAGA, Diana. 1989 Transculturación en Fernando Ortiz. La Habana: Editorial de Ciencias Sociales.

LAFONTANT, Jean. 1994. "Interrogations d'un métèque sur la sybilline et dangeureuse notion d'identité collective". Cahiers Franco-canadiens de l'Ouest, vol. 7, núm. 2. Manitoba: Collège de Saint-Boniface.

LARUE, Monique. 1996. L'arpenteur et le navigateur. Quebec: CETUQ / Fides.

LEBRUN, Monique. 1994. "L'interventionnisme de l'État québécois en matière linguistique". Échos. Pour comprendre la société francaise actuelle. París: CIEP.

LEMIEUX, Denise et al. 2002. Traité de la culture. Quebec: Les Éditions de L'IQRQ.

MAALOUF, Amin. 1998. Les identités meurtrières. París: Grasset.

MAILHOT, Laurent. 1996. La littérature québécoise. Montreal: Éditions Typo.

MARCOTTE, Gilles. 1992. "Le roman de 1960 à 1985". Le roman contemporain au Québec (1960-1985). Quebec: Archives des Lettres Canadiennes T. VIII Fides. 33-51.

MiLot, L. F. Dumont, dir. 1993. Pour un bilan prospectif de la recherche en littérature québécoise. Quebec: Nuit Blanche Éditeur.

MoISAN, C. R. Hildebrand. 2001. Ces étrangers du dedans, Une histoire de l'écriture migrante au Québec (1937-1997). Quebec: Editions Nota bene.

MORIN, M., C. Bertrand. 1979. Le territoire imaginaire de la culture. Lasalle: Hurtubise HMH.

NePVEu, Pierre. 1999. L'Écologie du réel, mort et naissance de la littérature québécoise contemporaine. Quebec: Boréal. 
Plourde, Michel, dir. 2000. Le Français au Québec. 400 ans d'histoire et de vie. Montreal: Fides, Les publications du Québec.

ProulX, Monique. 1997. Les Aurores montréales. Montreal: Boréal.

PRUD'Homme, Nathalie. 2002. La problématique identité culturelle et les littératures (im) migrantes au Québec. Mona Latif Ghattas, Antonio d'Alfonso et Marco Micone. Quebec: Éditions Nota bene.

RoBIN, Régine. 1983. La Québécoite. Montreal: Editions Typo.

SIMON, Sherry. 1994. Le Trafic des langues, traduction et culture dans la littérature québécoise. Montreal: Boréal. et al. 1991. Fictions de l'identitaire au Québec. Quebec: XYZ.

USLAR-PIETRI, Arturo. 1969. En busca del Nuevo Mundo. México: FCE. 